\title{
De Eisenstein a Bressane: genealogias de um gesto experimental
}

\author{
Sandro de Oliveira \\ Universidade Estadual de Goiás, Goiânia, GO, Brasil \\ ORCID: http://orcid.org/0000-0001-5717-8991
}

\begin{abstract}
Resumo
O trabalho do ator ocupa o centro de preocupações expressivas que são o front de pesquisas dentro do que se convencionou chamar de cinema experimental. Inúmeros realizadores e atores utilizaram uma vasta paleta de processos figurativos para expressar uma preocupação que perpassa quase toda a história do cinema experimental: o ato da visão pelo dispositivo cinematográfico e pela visão humana (personagem/ espectador). Este artigo descreve como atores e realizadores promoveram essa investigação figurativa sobre o motivo da mutilação ocular e suas variantes (enucleação, hemolacria, interferências sobre a película e cirurgias oftalmológicas) em filmes fora do enquadre teórico dos cinemas clássicos.
\end{abstract}

\section{Palavras-chave}

Ator. Cinema. Experimental. Mutilação ocular.

\section{Introdução}

Imagine um olho não governado pelas leis de perspectiva criadas pelo homem, sem preconceitos pela lógica da composição, que não responde ao nome de tudo, mas que deve conhecer cada objeto encontrado na vida através de uma aventura da percepção. (BRAKHAGE, Stan. Metaphors on vision).

Nos cinemas experimentais, tenham tido estes qualquer nomenclatura que o valha (vanguarda, marginal, underground, de poesia, de invenção, entre outros), o conjunto de gestos da mutilação ocular e suas possíveis variações (enucleação, hemolacria, interferências na película no local do globo ocular e cirurgias oftalmológicas) se manifestam como um gatilho da criação ou como uma chave-mestra que abre nossa percepção para esses filmes "estranhos". Na arte do ator, majoritariamente os de vertente experimental, o 
conjunto de gestos que chamo de mutilação ocular alude à visão da câmera ou câmeracineasta ou, por vezes, à visão do espectador ou do personagem-ator. Na fortuna crítica do cinema experimental, ora o ato ou a capacidade de olhar, como também o olho como forma orgânica ou tecnológica (o dispositivo cinematográfico), surge como uma espécie de leitmotif desses filmes, uma índole ou impulso vital que os explica.

Do formalismo das obras soviéticas dos anos pós-revolução de 1917 em Eisenstein, passando pelo surrealismo das obras de Buñuel-Dali até o cinema pós-novo de Júlio Bressane, há inúmeras cenas de filmes em que vemos várias formas que manifestam o poderio icônico do gesto da mutilação ocular, mas também imagens sobrepostas, prismáticas, caleidoscópicas, distorcidas, arranhadas, em negativo, perfuradas e reversas, revelando uma problematização da visão expandida ou embargada que o aparato cinematográfico e o corpo do ator podem materializar. Cenas que são registros de uma dúvida que persegue o artista experimental: os meus olhos e os dispositivos de registro mecânico veem a mesma coisa ou com a mesma acuidade? Wees (1992, p. 4) descreve algumas hipóteses adotadas por teóricos sobre a pesquisa do sentido da visão no cinema, algumas das quais serão analisadas em relação à arte do ator:

[...] como gestos de rebelião contra as convenções do cinema popular, como táticas de choque típicas da campanha de vanguarda para épater les bourgeois, como métodos formalistas de desfamiliarização, como novos códigos visuais substituídos pelos códigos tradicionais de narrativa e representação no cinema, como expressões de estados psicológicos e significados simbólicos, como experimentos para determinar as propriedades formais do filme, como formas de desmistificar o meio e antecipar seus materiais e processos de produção.

Comolli (2008, p. 247 - 248) advoga o fato de que o cinema da "inscrição verdadeira" pouco acredita na capacidade ontológica da câmera cinematográfica de produzir efeitos de realidade, sendo que o dispositivo cinematográfico está "irrevogavelmente destinad[o] à imperfeição na produção de efeitos realistas. Essa impressão de realidade fabricada pela câmera é apenas uma impressão, aproximação por ausência", pois a imagem é somente signo, mergulhado que está na sua inerente incompletude. 0 olho do espectador se mostra propenso a crer na capacidade da câmera de produzir imagens "realistas" e esta, por sua vez, está imersa na sua própria dúvida quanto ao real que produz:

No cinema, esse retorno do olhar para si é o retorno de um olhar passado pela máquina. 0 olho do espectador de cinema não controla de fato nada 
do espaço desvelado na tela de projeção. 0 olho do espectador é ele mesmo controlado pela representação particular dos limites, da profundidade e das distâncias que o olho não humano da câmera produz. (COMOLLI, 2008, p. 98 - 99). ${ }^{1}$

Há, por outro lado, uma potente história nas obras experimentais que nos leva às problematizações do cinema, da câmera-cineasta, como uma visão portadora de maior acuidade técnica em relação à nossa visão cotidiana. 0 cine-olho (kino-glaz) de Dziga Vertov (RENAN, 1967, p. 71) estabeleceu que "[...] o ponto de vista que o olho da câmera [...] via era uma realidade diferente e superior à realidade vista pelo olho humano", uma "liberdade de controle do tempo, espaço, e conteúdo, [que] não deveria estar restrita à representação da realidade do olho humano", instalando uma pesquisa ou hipótese de trabalho sobre a visão absoluta da imagem fílmica que era frontalmente oposta à de Comolli acima. Para Vertov, a visão permanece sempre o meio primordial de apreensão e de conhecimento do mundo, sendo que a tarefa do cinema seria então de "ver 'melhor' que os olhos" [...], "penetrar mais profundamente o mundo visível” (AUMONT, 1996, p. 47-48), numa obsessão ortoscópica que o cinema deveria perseguir, reiterando o que o realizador Stan Brakhge considera como o “compromisso da vanguarda com uma 'arte da visão' [que] localiza a fonte desta arte na 'percepção visual no seu sentido mais profundo'" (BRAKHAGE, 1963, não paginado). Ou, em outros termos, uma propensão de assimilar o olho à câmera (ou vice-versa) que levou Vertov a descrever os movimentos de câmera como equivalentes às habilidades oculares: a panorâmica, o travelling, o zoom, etc. Talvez uma reposição, em termos tecnológicos, da dialética entre Tirésias e Édipo: a câmera cinematográfica como um dispositivo que é mais do que um órgão de sentido, um canal por meio do qual o conhecimento além do da simples visão biológica se estabelece. Tirésias não tinha a visão biológica, mas o conhecimento além da vacuidade da mera visão orgânica das coisas, pois enxergava além, via o futuro. Já o último apreendia o mundo com perfeição ocular, mas lhe carecia a sabedoria dos que realmente "veem"; destituído que era da visão "superior", Édipo carecia do conhecimento ou de uma mínima clarividência, sendo então vítima da hybris (descomedimento) que "cega" o homem arrogante. Ambos são representações de um espelho invertido que põe em

\footnotetext{
${ }^{1}$ Há uma tradição teórica interessada na instalação do engodo ligado à câmera cinematográfica, no olhar que a imagem produz, em que os equívocos da nossa visão são o ponto de partida matemático para nos fornecer uma impressão de realidade para nossa percepção visual. Para Paul Valéry, um dos exemplos do quanto nosso olho pode nos pregar peças seria a percepção visual gerada pela cronofotografia, que reelabora muito do que percebemos na grafia, nos espaços e na matéria dos movimentos (ALBERA, 2012).
} 
contradição a visão ocular (fisiológico-orgânica) e a visão que gera o conhecimento pleno (para Vertov e Brakhage, o dispositivo cinematográfico).

O cinema surge, então, como uma máquina - technè optikè - não de inscrição, mas do ordenamento e análise do olhar que, na opinião de Dubois (2004, p. 36), funda "uma forma de figuração 'mimética' baseada na reprodução do visível", ou seja, como a grafia dos fenômenos se dava na organização dos elementos pró-fílmicos produzidos pelo dispositivo cinematográfico. Torna-se sugestivo, contrariamente, no cinema experimental, o enorme número de lentes sujas de câmera, lentes anamórficas ou filtros que dificultam uma visão plena do "objeto" pró-fílmico. Podem também ser usados filtros, diafragmas, sobre e sobimpressão que são procedimentos que permitem ao cineasta experimental modificar, transformar ou transubstancializar o mundo filmado e, por consequência, distanciar a representação do representado, de insistir sobre o ato criador antes do que sobre a coisa criada (MITRY, 1974). 0 ato criador motiva e explicita esta nova visão das coisas, que o ator experimental traz à tona com a figuração do olho mutilado.

Assim, na já longa história do cinema experimental, desde os "ismos" da vanguarda europeia dos anos de 1920, houve uma linhagem pregnante de investigações no campo do jogo do ator que revela essa urgência de realizadores experimentais de por o olhar/ a visão, seja ele (a) do dispositivo ou do ator-personagem, no front de preocupações do cinema: um olhar para o mundo, mas um olhar "com ressalvas", pois o artista experimental acredita que as ciências e artes modernas (entre elas o cinema) apelam para princípios do relativismo, da probabilidade, e não das certezas dos modelos clássicos, das estruturas cambiantes e em progresso, da inclusão de elementos que efetivam sua forte propensão intertextual e desconstrutiva, utilizando parâmetros dissimétricos, incongruentes e que se chocam com as noções engessadas de "verdade" e de "real" (MAUSS, 2003).

O objetivo deste artigo é investigar de que modo a permanência de certas genealogias figurativas e a retomada recorrente de estereótipos visuais dos vários gestos da mutilação ocular contribuem para uma história estilística e metodológica das formas e técnicas do jogo do ator ligadas a esse gesto como investigação do sentido da visão (do dispositivo, do personagem e do espectador) nos cinemas fora do enquadramento estético e institucional do que se convencionou chamar de "arte cinematográfica clássica" (BORDWELL; THOMPSON; STAIGER, 2005). Com um corpus de filmes tão amplo, a minha chegada nas figurações experimentais da mutilação ocular se deu por método dedutivoassociativo, ou seja, a partir de manifestações do modus operandi do artista experimental no 
cinema, em áreas múltiplas da produção fílmica (montagem, direção de arte, fotografia, encenação), chegou-se aos casos particulares da manifestação do jogo experimental do ator, imerso neste arcabouço caleidoscópico de saberes entrelaçados na produção fílmica. Num primeiro momento, discuto como imagens-arquétipos da mutilação ocular surgiram nos cinemas experimentais e deram origem à expressão de uma "angústia criativa" que permanece, até muitas décadas depois, como preocupação estética e tecnológica intensas para realizadores e atores dentro do cinema experimental. Após essa discussão, faço uma análise evolutiva de como o gesto arquetípico da mutilação ocular se transforma em código dentro destes cinemas, migrando para manifestações que revelam verdadeiras filiações artísticas e estéticas dentro dos cinemas experimentais.

\section{Imagens-arquétipo de $O$ encouraçado Potemkin/ Um cão andaluz}

O cinema experimental procura, desde as vanguardas europeias dos anos de 1920, expressar outras maneiras de operar o sentido da visão na sua acepção mais profunda e estrita, já que esta abarca muitas maneiras diferentes de perceber o mundo dos fenômenos. No que tange o aparato cinematográfico, de acordo com os primados formalistas dos cineastas da vanguarda, há uma miríade de "visões expandidas" dos fenômenos que alargam nossa percepção e nos advertem do caráter absolutamente caótico e multifacetado da produção imagética experimental: interferências na película (ou imagem digital), na lente ou sobreposição de filtros, pixilação da imagem, montagem disruptiva ou digressiva, filme em negativo, montagem estrutural, entre outras.

No caso do olho do ator, este se torna, para Aumont (1996, p. 47), uma paradoxal "janela da alma" que extravasa a angústia figural que pode ser tanto do personagem/ator quanto do realizador, já que a visão é

[...] extraordinariamente fecunda e suspeita ao mesmo tempo [...]. A visão espontânea, aquela nos nossos pobres olhos, é ao mesmo tempo frágil, insuficiente ao ver tudo sem próteses, e ao mesmo tempo 'rica', porque saturada de prejulgamentos culturais e ideológicos.

O olho humano é apenas um ou o primeiro circuito no caminho da imagem, pois esta se forma realmente no cérebro. É preciso, na concepção da vanguarda, compreender a pulsão escópica ou a escopofilia, diferentes, na opinião desses cineastas, do simples prazer de ver. Guarda-se uma convicção nas hostes experimentais que estamos dotados de 
capacidade cognitiva muito mais apta a compreender imagens, muito mais complexas e inquietantes do que o entretenimento comercial nos fornece. Tyler (1995) advoga a opinião de que os cineastas experimentais têm mantido o desejo de usar o dispositivo cinematográfico e o jogo do ator como instrumentos para ir além do biologicamente visível e penetrar mais fundo no "real" além das superfícies enganadoras e de fácil fruição do entretenimento industrial cinematográfico. Surgem, então, já no cinema soviético pósrevolução de 1917 e no ocaso do surrealismo na Europa, várias imagens de mutilação ocular que se tornam um arquétipo para toda uma linhagem de gestos que têm a mesma preocupação: questionar a capacidade do cinema de produzir uma inscrição do real, de por o olhar da câmera e do espectador sob litígio.

0 primeiro momento em que deparamos com uma mutilação ocular com esses intentos é no filme $O$ encouraçado Potemkin (1925), quando na longa sequência da carnificina na escadaria de Odessa, vemos uma mulher (N. Poltavtseva) com os olhos sangrando, vítima da ação criminosa da guarda czarista durante o motim dos marinheiros no navio, motim esse que se espalha pela cidade. 0 sangramento dos olhos da mulher com os óculos estilo pince-nez pode ser avaliado como um evento absolutamente inserido dentro da trama do filme, sem alguma outra possibilidade de leitura mais acurada. Pode ser, mas não é a única maneira de vermos a cena, porque antes do plano da mutilação ocular exatamente três planos antes - temos uma outra imagem que mostra, ao estilo mais reflexivo possível, o modus operandi experimental por essência: outro plano de um jovem segurando um espelho ao lado do rosto. Plano que conceituaria como "de investigação da fatura" e que expõe a índole do filme de Eisenstein: um estudo da materialidade da imagem e a sua posterior suspeição. 0 uso do espelho como tábua de confissões, de exposições do interior da personagem ou como suporte de uma simbiose do (a) ator/atriz pode tornar-se aqui um gesto pleno de camadas de significação para a teoria do jogo do ator, já que seus usos, programas e princípios são múltiplos e polissêmicos. O espelho funciona como elemento reflexivo por excelência, de um cinema que se volta para si mesmo, e que investiga e pesquisa seu próprio gesto criador e seus materiais (dispositivo e elementos pró-fílmicos). 
Figuras 1 e 2 - A reflexividade do espelho e a mutilação ocular em $O$ Encouraçado Potemkin.
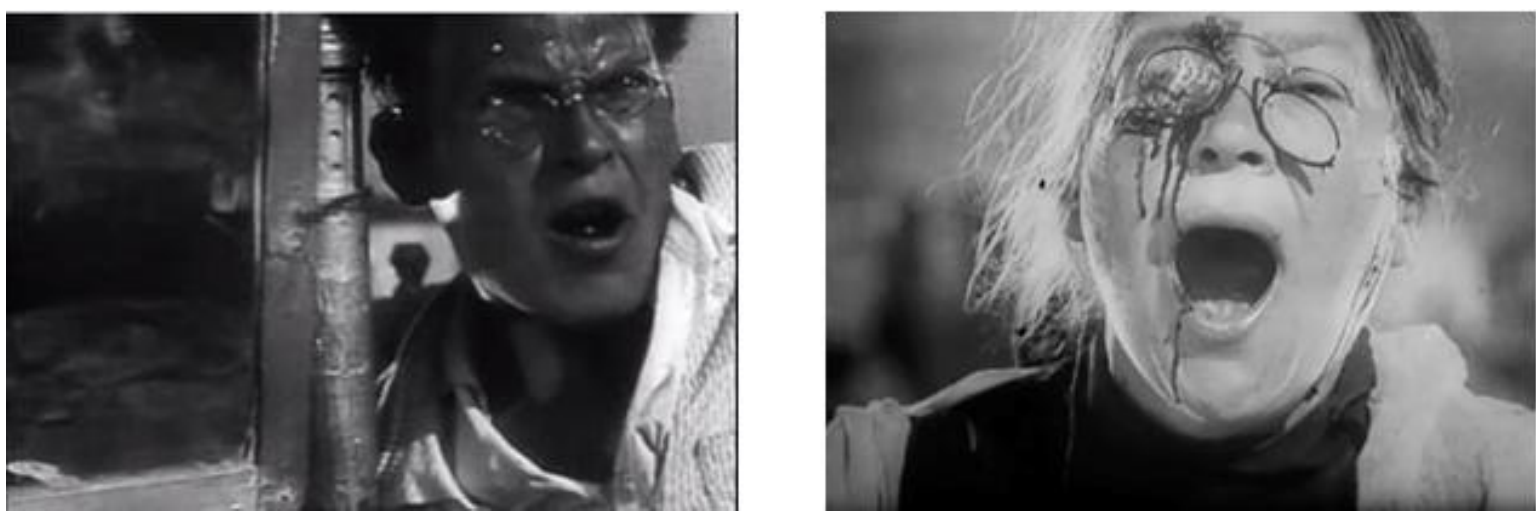

Fonte: O encouraçado Potemkin (1925), capturas de imagens.

Três planos depois da imagem do jovem segurando o espelho, na mesma feérica sequência da escadaria, temos o close-up da mulher com o olho mutilado: imagem que se tornou quase icônica da própria história do cinema. 0 que proponho aqui não é ler o plano da mulher com o olho mutilado de maneira isolada, mas em relação intrínseca com esse outro plano, o do rapaz na frente do espelho. A relação entre esses dois planos pode ser uma possível chave do cinema estrutural de Eisenstein e de outras correntes experimentais. Eisenstein nos afronta com uma imagem da mutilação e com um espelho, problematizando a própria imagem do filme, colocando-a em primeiro plano para averiguação: Será ela real? De que matéria é feita? E tantas outras questões daí decorrentes, inclusive as questões do entrecho fílmico que $O$ encouraçado Potemkin nos oferece: uma revolta popular no ocaso da Rússia czarista. $\mathrm{O}$ ator aqui "se mostra" e ao mesmo tempo mostra a imagem do espelho para o público, provocando assim nossas reações e inquietações: Devemos acreditar no que vemos? Naquilo que é refletido pelo espelho? Talvez mais do que isso, o espelho nos coloca de frente com a questão do cinema ser um medium, um elemento que se interpõe na nossa relação com o real e que impõe camadas entre nós e a trama do filme, sugerindo uma espectatorialidade mais calcada na suspeição e na investigação do que propriamente na catarse. Por fim, este diálogo entre esses dois planos nos faz concluir que o gesto da mutilação ocular é um gesto propositivo, pois nos remete ao plano do espelho como um comentário sobre a reflexividade fílmica.

Três anos depois de Eisenstein, temos a mutilação do olho da jovem mulher (Simone Mareuil) em Um cão Andaluz (1928). Diferentemente de Eisenstein, o elemento pró-fílmico propositor do questionamento da imagem não é somente a performance de uma atriz, mas do próprio diretor do filme que, numa espécie de cameo appearance, demonstra ser ele 
executor deste gesto propositor de por a imagem fílmica em evidência. Ela nos liga a uma necessidade duradoura dos cinemas experimentais de tentar apreender um mundo na sua ontologia, na sua inteireza, integridades essas somente encontradas, segundo seus realizadores, em filmes que usam a imagem para por em suspeita a lisura dela mesma, no espírito da época das vanguardas dos anos 1920 e 1930: investigação da materialidade do filme, suspeição dos primados da ficção e da anedota. Essa visada teórica da recusa da ficção nos leva, consequentemente, para a instalação do cinema dos sentidos, um cinema que quer problematizar o próprio ato da visão do ator (e, por consequência, o do espectador), só que esses filmes questionam esta visão na sua própria fonte, numa tentativa de dizer que o dispositivo e o conteúdo pró-fílmico (com a atriz - ou uma cabra ou um burro, posteriormente - sendo usado como objeto) estão como que sob litígio.

Figuras 3 a 6 - Um cão Andaluz: imagem-arquétipo da visão sub judice.
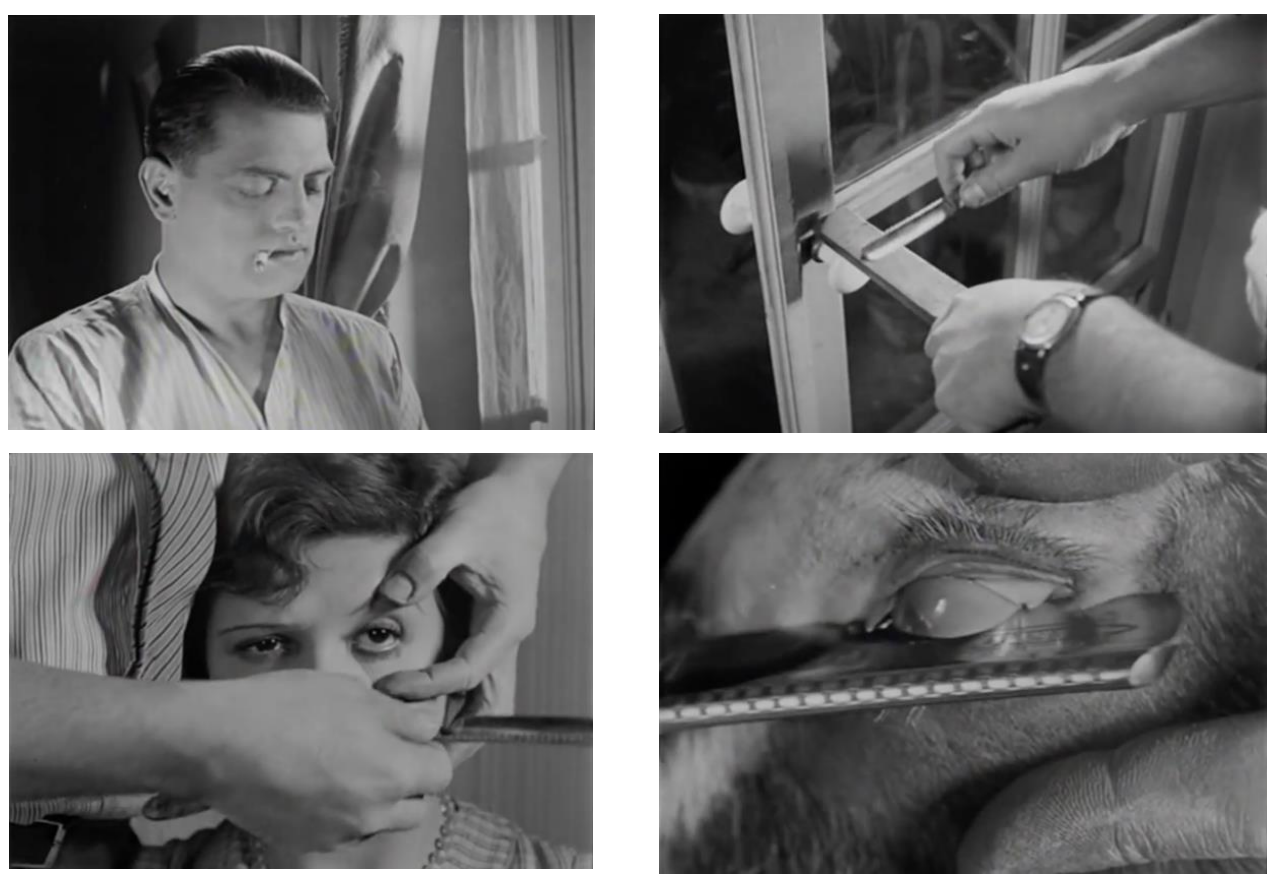

Fonte: Um cão Andaluz (1928), capturas de imagens.

Albera (2005, p. 68) afirma que o lugar dos cineastas surrealistas ocupado tardiamente por Buñuel e Dali deve antes de tudo ser ligado

[...] às convicções doutrinárias do movimento: recusa da ficção, do romance, dos efeitos artísticos, vontade, em suma, de ultrapassar a arte em direção a uma verdade documental - o documento podendo ser de natureza psíquica. 
Há uma ambiguidade, no entanto, nesta afirmação de Albera, já que ao lado dessa urgência pelos aspectos materiológicos da imagem e a rejeição da anedota e de truques do dispositivo, havia também um movimento inconteste dos surrealistas (e mais tarde outros realizadores vanguardistas) em direção a imagens que nos exibem os mecanismos do sonho, expondo a sua opacidade e não a sua clareza. Já Sitney (1987, p. XIX) considera Um cão Andaluz como um dos "mais puros exemplos de cinema surrealista, que rejeita a exploração de imagens engendradas pela câmera. [...] É como se a câmera tivesse o mesmo acesso ao mundo visível que uma vidraça". De fato, no meio do filme, o protagonista olha um acidente de carro pela vidraça da janela, essa servindo como uma "barreira através da qual o mundo visível entra, mas não pode ser transposto [sendo] um ícone da concepção de Buñuel e Dali do cinema" (SITNEY, 1987, p. XIX).

Os realizadores de Um cão Andaluz, no entanto, não cessam de hipersemiotizar o olho do ator como veículo desse questionamento do olho mecânico do maquinário cinematográfico e da percepção visual humana como um instrumento voyeur (orgânicos ou não). No close do personagem masculino (Gaston Modot) em A idade do ouro (1930), há um investimento no olho do ator como elemento significante de uma angústia que pode ser lida em duas vertentes: as frustrações amorosas do personagem, que "sangra" pelo amor não realizado, encapsulado num filme que não cessa de questionar a ambiguidade do poder de registro imagético do cinema, suas ranhuras e incoerências.

Figura 7 - 0 ator sangra pelo olho em $A$ idade do ouro: frustração e ambiguidade de registro.

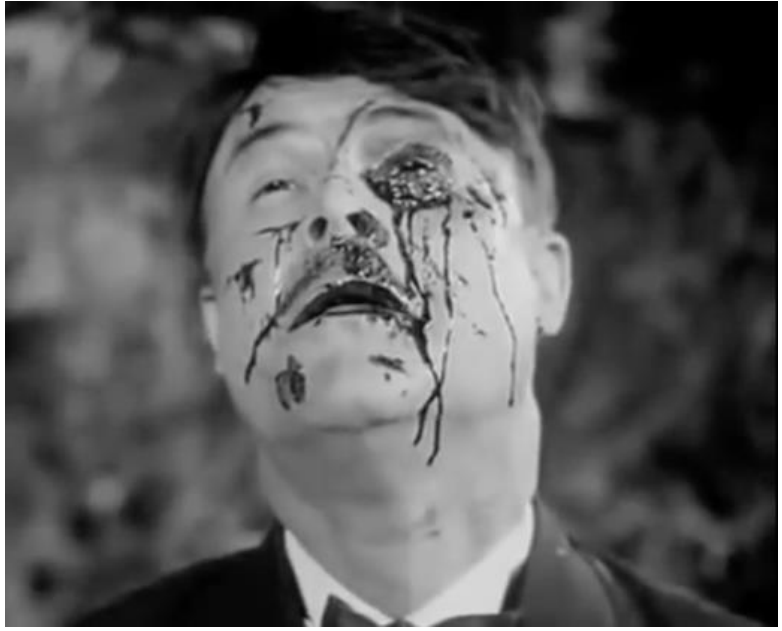

Fonte: A idade do ouro (1930), captura de imagem. 
Com a forma paratática de Um cão Andaluz e A idade do ouro, Buñuel e Dali (aqui como roteiristas) expressam a inerente incapacidade desses filmes tão fragmentados em relatar acontecimentos encadeados em lógica narrativa minimamente apreensível, destituídos que são de conexão causal. A performance dos atores com seus os olhos dilacerados materializa esse desprezo pelo registro de um real domado pela "razão", um desapego pelo traço artístico mimético e uma apreensão e organização não usual dos fenômenos, ataque óptico desses filmes materializado por dilaceramentos oculares.

\section{Evoluções de uma figuração: hemolacria e interferências na película}

Não são poucos os momentos na vanguarda em que atores surgem com os olhos sangrando ou a película é arranhada exatamente no campo dos olhos, enfatizando essa identificação profícua entre realizador - que interfere na película -, o rosto do ator e o dispositivo fílmico. Tornam-se, então, ilustrativos os momentos em que os atores de Reflections on black (1955), Visual training (1969) e Família do barulho (1970) têm seus olhos sangrando, numa espécie de hemolacria sinedóquica, levando a performance do ator a figurar uma alegoria macroscópica: os olhos são instrumentos de uma obsessão que pode ter origem tanto nos trâmites do personagem quanto na enunciação, podendo revelar também "metáforas da visão" dos seus realizadores. Estas estão baseadas numa premissa simples, mas ao mesmo tempo ousada de Kittler (2010, p. 35 - 36): não sabíamos nada a respeito dos nossos órgãos sensoriais até que os meios técnicos, as mídias, nos propuseram, pela miríade de dispositivos possíveis, vários modelos e metáforas para comparação. As mídias técnicas são modelos para os órgãos sensoriais humanos precisamente porque "foram estrategicamente desenvolvidas para superar os sentidos".

Em Reflections on Black, ao arranhar o filme sobre os olhos de um homem cego, Stan Brakhage se dá o direito de ser uma espécie de "fornecedor ou árbitro da luz" (RENAN, 1967, p. 98), havendo aqui uma identificação incomum entre a ação do cineasta e a potência simbólica da imagem do ator na tela. Portanto, se a câmera para Kittler supera tecnicamente a capacidade de apreender os fenômenos em relação ao olho humano, Brakhage (1963, não paginado) pregava um olho não tutelado através de uma câmera não chancelada por conformações simbólicas que a engessavam numa visão constrita do "real". 
Toda a minha experimentação no cinema tem sido direcionada para a descoberta de modos de expressão não relacionados com outras formas de expressão. Estou procurando formas artísticas fílmicas puras, formas em nenhum modo dependentes da imitação de formas de arte existentes e nem dependentes do uso da câmera como olho.

Mesmo que as interferências venham autoconscientemente da enunciação, no caso do filme de Brakhage, ou se tornem graficamente visíveis no mundo diegético das personagens, nos outros exemplos, o ator figura nesses filmes uma impossibilidade de apresentar as imagens produzidas mecanicamente como facilmente "críveis". O filme de Brakhage então se revolta contra herança recebida da indústria clássica - criar uma realidade ficcional para o registro da câmera e produzir uma imagem comparável ao mundo que vemos - e revela, por conseguinte, uma onda nos cinemas experimentais de interferências ópticas no filme, na granulação da imagem, nas diferentes viragens em sépia durante o processo de revelação e fixação, na fragmentação do quadro e por imagens trêmulas geradas por manipulação propositalmente instável da câmera, algumas dessas presentes em Reflections on black.

Figuras 8 a 10 - Hemolacria e interferências na película.
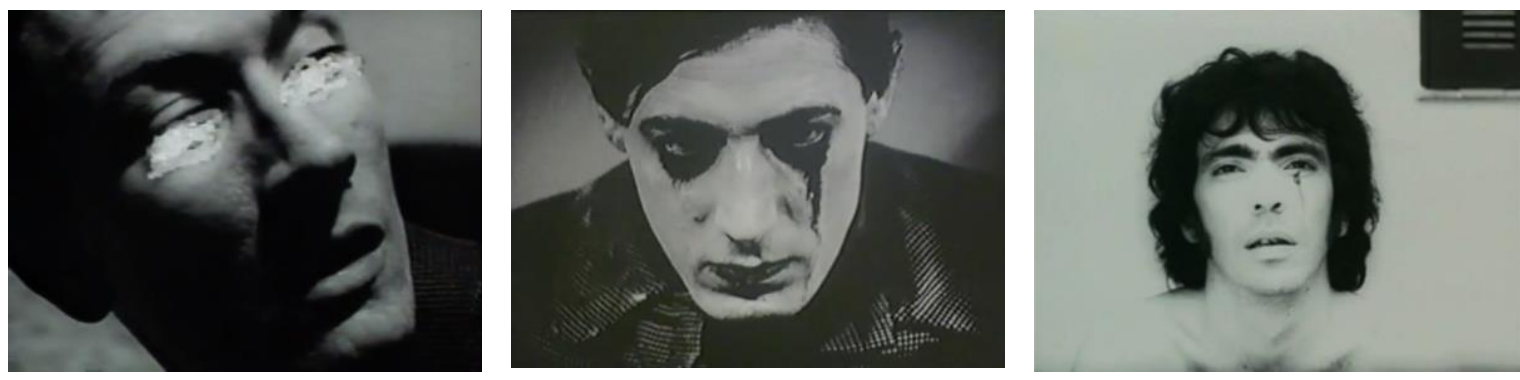

Fonte: Reflections on black (1955), Visual training (1969) e Família do barulho (1970), capturas de imagem.

É sugestivo o fato de que em muito do que se foi até hoje produzido teoricamente sobre o cinema experimental, as leituras que se fazem desses filmes dão conta de aspectos muito localizados de suas (possíveis) tramas, não conseguindo se fixar num movimento de pensamento, um zeitgeist, que perpassa muito da produção experimental: que a visão da câmera/cineasta ou do personagem/ator são, na verdade, materializações de um mundo imagético muito mais híbrido, heterogêneo e caótico do que resulta da visão mimética pura e simples das produções clássicas ou industriais, interessadas em produzir uma imagerie que resulta de racionalidade cotidiana rasa dos "realismos" cinematográficos. 
Persistem em surgir no cinema experimental o que P. Adams Sitney (1980) chama de filmes líricos, mitopoéticos ou estruturais, onde se dá espaço muito mais para imagens mosaicadas, fraturadas (imagens em split screen ou "olho de mosca" entre elas), dando ensejo a verdadeiras epopeias à loucura ou ao desarranjo mental. É exatamente na fratura entre os fotogramas que se instalavam as ilusões e inaptidões ópticas do espectador cinematográfico, preso entre a dicotomia opressora do olho humano que procura a estabilidade e o equilíbrio, tentando fazer deles um caminho para a compreensão do mundo visual, mas que encontra em muitos filmes experimentais (mas não somente neles!) a irregularidade, a elipse, o descontínuo ou ilusões ópticas explosivas, gerando o desconforto.

Os cineastas experimentais têm sob seu poder duas opções pregnantes em relação ao estatuto do cinema como dispositivo produtor de imagem gerada mecanicamente: questionar sua legibilidade como percepção visual ou apresentar o "real" como domado como fazem os cinemas naturalistas. O protagonista de Traité de bave et d'éternité (1951), ao revelar a fúria criativa do filme, prova que muitos realizadores experimentais escolheram o caminho do choque ao espectador como prova do modus operandi experimental:

Gostaria de fazer um filme que vos faça mal ao olho, realmente, como durante o desenvolvimento destas velhas projeções que se cortam e se destroem e de onde se veem os números 1, 3, 5, 7 a toda velocidade. [...] Eu deixarei os relâmpagos/ lampejos atravessar a película para devastar/ fulminar, chamuscar/ queimar a retina dos espectadores [...]. (TRAITÉ..., 1951, não paginado).

Outra via possível para colocar o mundo visível como objeto de um olhar que o obstaculiza ou rejeita mais do que fornece pistas claras dos fenômenos visíveis seriam os personagens de inúmeros filmes experimentais, das mais variadas cepas, em que o olho mutilado revela as frustações dos personagens, sejam elas de vários matizes, num processo de sobrevivência iconográfica e gestual que se "beneficia de uma fortuna expressiva toda particular" (DAMOUR, 2014, p. 17) como em gestos de abatimento psicológico, frustração ou, como nomearia Teixeira (2011, p. 173) sobre o cinema de Julio Bressane, uma "cirurgia da crueldade". 


\section{Do arquétipo ao gesto codificado}

Nas vanguardas dos anos de 1920, entre elas o expressionismo, o olho torna-se um elemento corporal que materializa o foco moral para o sentimento do personagem que, na opinião de Godard (1952), é o órgão que tudo se permite dizer, negar e perscrutar: é o elemento-mestre do jogo do ator. Nos cinemas experimentais pós-Segunda guerra, o jogo do campo-contracampo nos carrega para uma constatação da pouca mobilidade do olho no complexo de órgãos do rosto, que nesses filmes carrega consigo muito mais do que uma plástica, mas também uma potente ideia. Foi assim que em Funeral parade of roses (1969), a banalidade da trama de amor frustrada de um homossexual nos é mostrada com tons barrocos, com uma figuração da perfuração ocular que é feita, dentre os vários momentos do jogo do ator, na frente de um espelho.

Em The way to shadow Garden (1954), Stan Brakhage exercita o que ele chama de metáforas sobre a visão, quando o protagonista, estupefato pelas frustrações da adolescência, arranca ambos os seus olhos e o filme passa, então, a ilustrar o resultado do que o olho humano vê quando a imagem de contracampo se torna 'negativa', mostrando suas visões alucinatórias de um "mundo cromaticamente ao contrário". Este, ao inverter os valores ópticos da imagem, nos revela um "não-ser", um mundo da morte ou do desaparecimento, nos lembrando da origem material do filme que assistimos, mas ao mesmo tempo revelando o avesso, o reverso e o contrário da imagem que o filme nos fornece, distanciando-se e rompendo com os trâmites da representação clássica anódina: nas palavras de Brenez (1998, p. 79), o negativo nos reenvia à "radiografia, [ele] exuma o por dentro das coisas".

Torna-se absolutamente sugestivo o fato desses dois filmes, produzidos em países tão distantes e em épocas também diferentes, tenham se interessado pela mutilação ocular que opera uma intercambialidade figurativa explícita para manifestar uma angústia criativa que é característica não do (melo-)drama juvenil dessas obras, mas do esforço comum desses cineastas em professar que fantasia e visão fisiológica se misturam em incidentes de frustração erótica. Damour (2014, p. 24) advoga a presença de gestos codificados na história das formas atorais como uma

[...] longa tradição iconográfica, gestos que oferecem, portanto, uma leitura imediata e tendem a se tornar verdadeiras fórmulas congeladas, usadas por seu forte significado estético (sua forma estilizada acentuando a valência plástica de planos cuidadosamente compostos para acomodar sua 
emergência), mas também por seu poder retórico (sua chegada é esperada em certos momentos-chave da organização semântica do filme, transformando-os em verdadeiras figuras de estilos visuais).

Figuras 11 a 14 - Intercambialidade figurativa em Matsumoto e Brakhage.
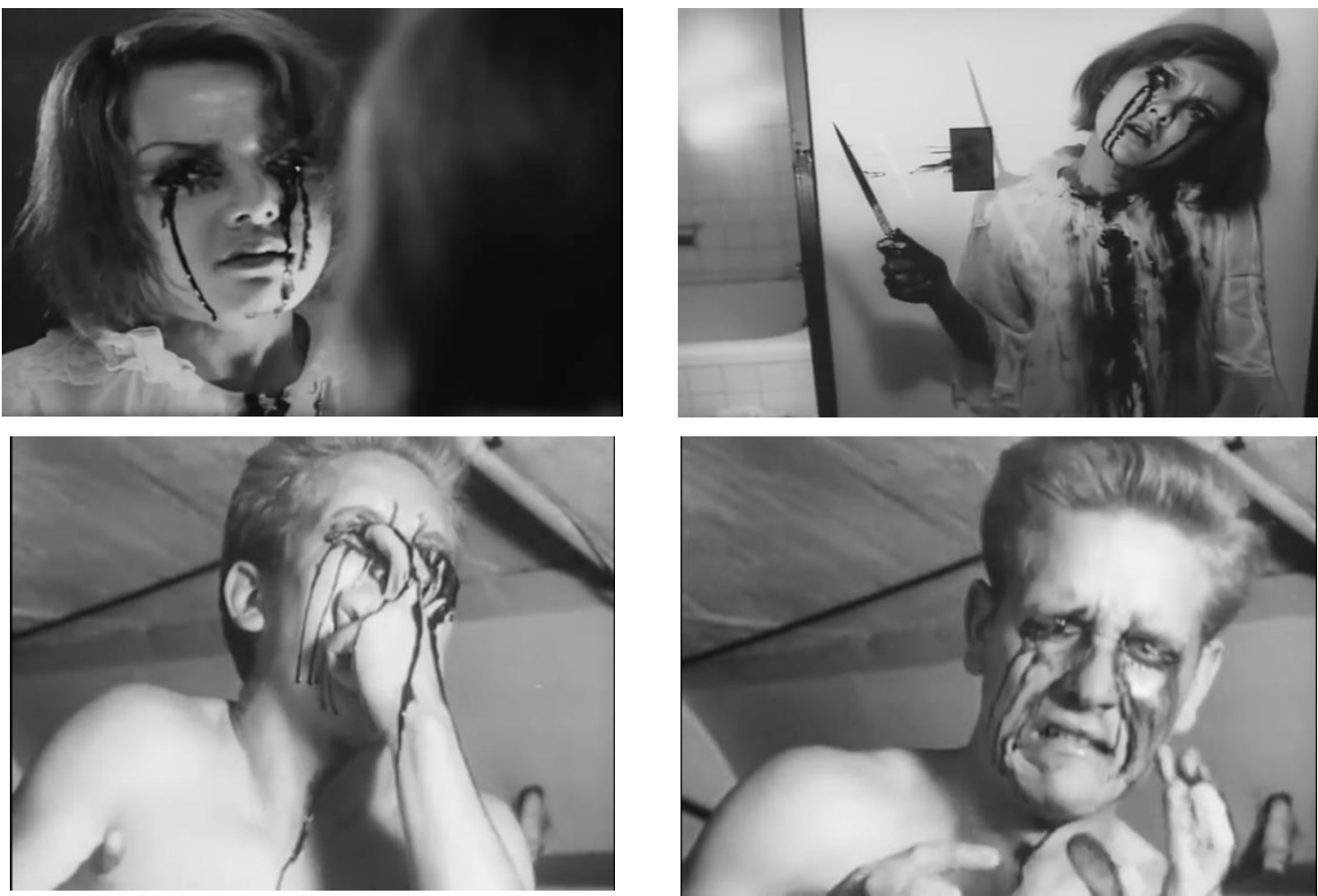

Fonte: Funeral parade of roses (1969) e

The way to shadow Garden (1954), capturas de imagens.

No filme de Brakhage, um plano que figura um flash forward metafórico do jovem personagem - interpretado pelo ator Walter Newcomb - quando do ato da mutilação ocular se mostra como uma premonição não somente da automutilação que irá acontecer, mas também do fato de que o rapaz encontrará o apartamento/mundo como um espaço de estranhamento. No primeiro movimento de câmera em panorâmica no início da sequência que abre o filme, vemos as janelas do apartamento do rapaz pelos olhos da câmera, mas imaginamos que é também possível que o rapaz já seja capaz de ver as janelas de onde ele está. Quando a câmera termina o movimento de panorâmica nas janelas do apartamento, vemos duas lanças em cada vidraça, certamente a parte mais alta da grade de metal que separa o prédio da rua, como dois olhos sendo "espetados por lanças pontiagudas". 
Figura 15 - Flash forward das lanças na janela: premonição da mutilação dos olhos?

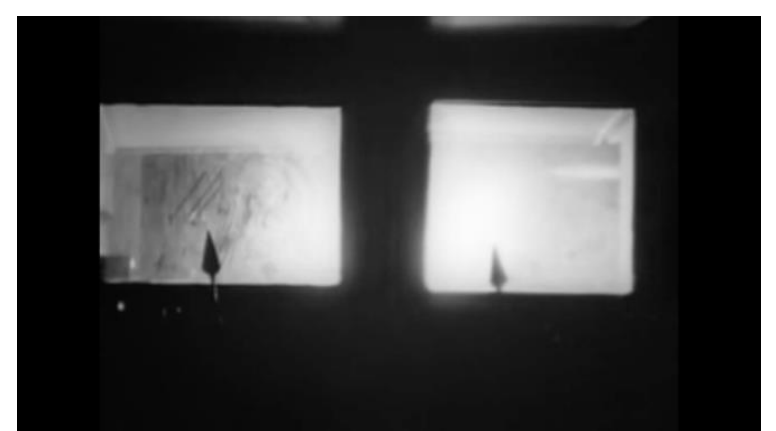

Fonte: The way to shadow Garden (1954), captura de imagem.

A frustração erótica como fator de ignição de gestos de mutilação ocular também foi farto material para as pesquisas sobre o campo da visão de Julio Bressane. Num filme quase que contemporâneo ao de Matsumoto, Amor louco (1971), o ator Guará Rodrigues se automutila como numa cirurgia grotesca nesse gesto que se tornou, ao longo do tempo, uma espécie de gesto-epíteto no cinema experimental, investigação sobre "o olho \& o olhar. Operação de catarata no olho da linguagem do cinema. Olhar incomum em ângulo inaudito. Filme sobre a retina que me tirou da rotina [...] interpenetração olho/ visor da câmera" (FERREIRA, 2000, p. 189). É notável como Bressane opera na sua obra uma interpenetração de temas e vetores visuais conectivos que fazem, estranhamente, uma cena em um filme comentar, se impregnar ou oferecer uma outra alternativa a outra cena em outro filme, num ciclo de autocomentários cinemáticos que transformam sua obra num caleidoscópio de figurações em eco. Em $O$ rei do baralho (1974), Bressane liga o gesto da mutilação ocular de dois anos antes a um gesto de "extração" que é, igualmente ao anterior, gerador de um desconforto extremo ao espectador. Uma jovem mulher está em close-up numa postura em 3/4 para a câmera, voltada para a sua direita e, na frente de um de seus olhos, veem-se as pontas de uma tesoura no gesto ameaçador de furar ou extrair seus olhos: uma espécie de tesoura-pinça cirúrgica. 
Figuras 16 e 17 - A enucleação da cirurgia da crueldade em Bressane.
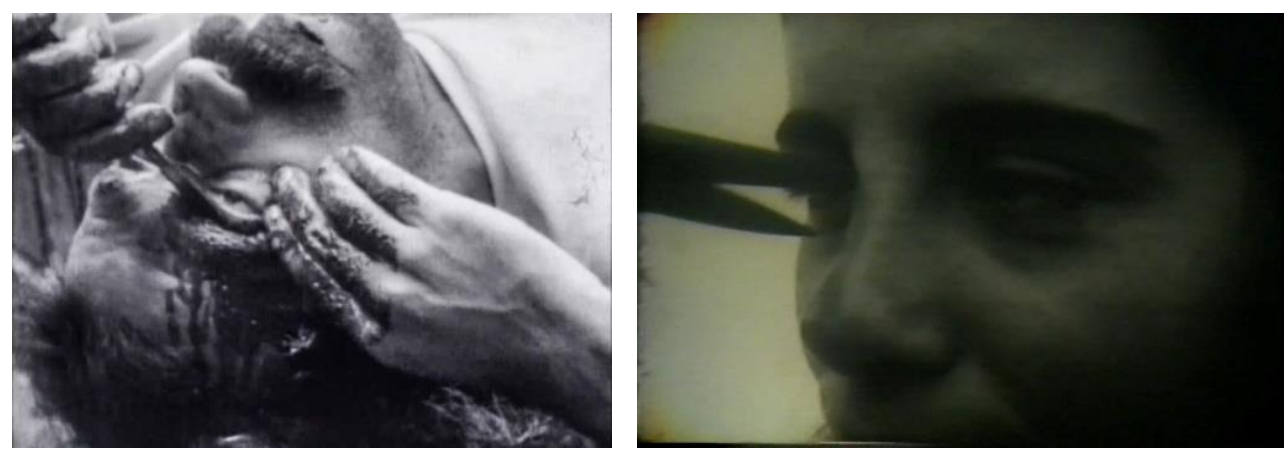

Fonte: Amor louco (1971) e

O rei do baralho (1974), capturas de imagem.

Se investigarmos essas duas figurações como constituintes de um grupo de preocupações do realizador, veremos que, independentemente do objeto cortante utilizado, "tal especificidade instrumental é o que afigura o atravessar da visão, sua extirpação, sua suspensão, abrindo acesso à cavidade ocular vazia, limite extremo da cegueira, antevisão, vidência" (TEIXEIRA, 2011, p. 174). Constata-se, então, que há uma índole criativa no cinema experimental interessada numa visão que vai além da capacidade ocular, indo para as ambiências do espírito, que faz o dispositivo cinematográfico cumprir funções proposicionais de pensamento, uma espécie de demiurgo. São frequentes, portanto, na obra de Bressane, essas armas e objetos cortantes que

[...] assumem uma intensidade mágica, na medida em que 'apagam' as vítimas sob os estados de transe de seus usuários. [...] Sua instrumentalidade, no entanto, é obra performática, no sentido de que já não alvejam um corpo cotidiano, mas o corpo enquanto objeto de um cerimonial. [...] A tesoura-pinça irrompe num ambiente de pura teatralidade, com todos os preparativos de uma cerimônia que tende ao ultrapassamento da mera representação (um além da consciência), em busca de um aquém da contemplação, desse lugar vazio que se esconde por detrás do olho. (TEIXEIRA, 2011, p. 413 - 414).

Para Bressane, o olho é também um órgão que vaza ou expõe o que está dentro do corpo, ou seja, dentro da visão do personagem, direcionando essas figurações para os mesmos questionamentos da cirurgia da crueldade executada por Buñuel e Dalí em $O$ cão Andaluz. Geraldo Veloso (1983, não paginado) chama essas figurações em Bressane de cinema da retina, uma "auto-dilaceração por um grande amor desesperado é acompanhada por uma autocirurgia em busca da abertura do campo visual". Assim, Bressane fornece um 
resumo e ao mesmo tempo, nessas cirurgias da retina, das pesquisas de Buñuel-Dalí, mas também de Brakhage e Matsumoto.

É possível, contudo, tecer interfaces entre Júlio Bressane e outro pensador contemporâneo à produção de muitos filmes analisados aqui (décadas de 1960 - 70), que pôs em evidência a substituição do olho humano, da visão biológica, por uma visão prostética de um órgão sensorial: Marshall McLuhan. Este filósofo canadense acreditava que a mídia havia tomado a função fisiológica (natural) humana, considerada por ele altamente descartável. Assim, a câmera seria um olho dotado de lentes, filtros, dispositivos de foco, zoom, entre outras funções, que efetiva um trabalho que para ele é paradoxal, pois ao mesmo tempo que age como um olho tecnizado, a câmera amputa a sua origem biológica para potencializar as suas capacidades tecnológicas. ${ }^{2}$

\section{Considerações finais: heranças e filiações figurativas}

Uma constatação motiva particularmente este trabalho: uma hipótese de que mesmo dentro das restrições e isolamentos econômicos e institucionais do cinema experimental, é possível observar a recorrência de figurações no jogo do ator, emergindo certas linhagens de pesquisas que impregnam um considerável grupo de realizadores dentro do que se convencionou chamar pelos críticos e teóricos de cinema experimental. Cada obra cinematográfica pende, então, de polos antagônicos: pode ser considerada uma obra única (orgânica) e absoluta e, ao mesmo tempo, "pertencendo a um sistema de relações complexas, fazendo 'convergir nela as energias das civilizações'” (DAMOUR; VALMARY; VIVIANI, 2011, p. 9). Esse sistema de relações é o que motiva uma boa parte da produção teórica sobre o jogo do ator, imerso que está em fazer surgir dentro de si a dicotomia que move muito da produção artística: ora imitar ou reproduzir figurações já codificadas, mas também experimentar e pesquisar novos caminhos.

Esses ecos da gestualidade enfática da mutilação ocular - em toda sua fortuna expressiva - promovidos por esses atores criaram dentro do cinema experimental uma pregnante herança de pesquisa que influenciou uma enorme gama também de realizadores, promovendo a criação de imagens, figuras e gestos que, parecidos ou relacionados à (auto)mutilação ocular, fizeram evoluir a pesquisa e utilização recorrente do mesmo gesto

\footnotetext{
2 Amputação esta que é aqui interpretada no jogo do ator em Bressane. Esta discussão sobre a visão de McLuhan e as mídias técnicas está em KITTLER, 2010, p. 29-30.
} 
de enucleação, seja ele experimental ou não. São ilustrativas, nesse nosso intento de enumerar essa genealogia atoral, a retomada quase ipsis litteris do gesto da cirurgia da crueldade, de Buñuel-Dalí e também de Bressane. Duas produções de momentos diversos da vanguarda norte-americana - dos primórdios da cinematografia experimental em Even as you and I (1937) e também já na sua ambiência estrutural do underground dos anos de 1960 em $T, O, U, C, H, I, N, G$ (1968) - receberam de Buñuel-Dalí material para uma satírica e bemhumorada homenagem ao papel das vanguardas no cinema.

Figuras 18 a 23 - Even as you and I e T,O,U,C,H,I,N,G como sátiras a Buñuel-Dali.
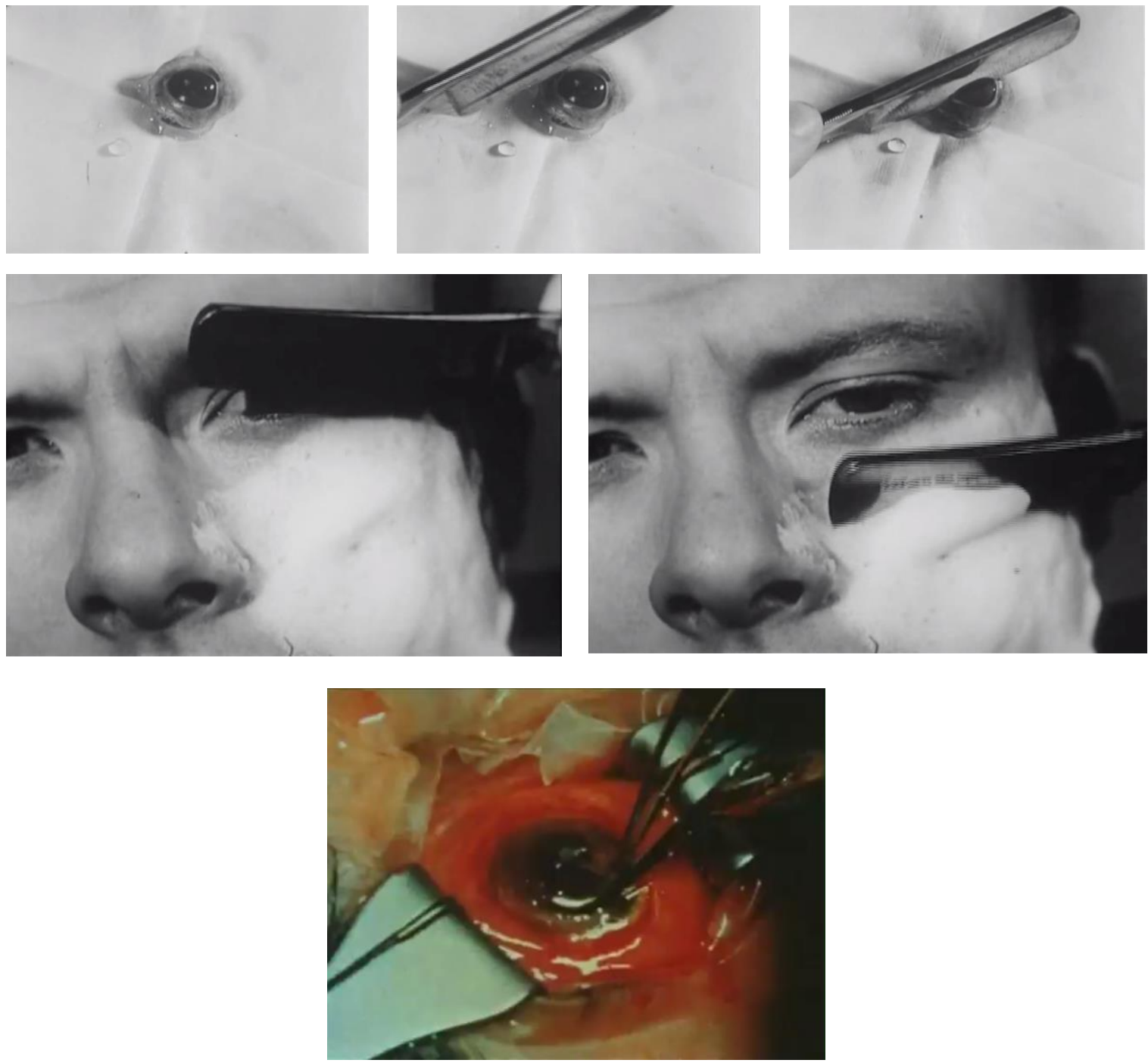

Fonte: Even as you and I (1937) e

$T, O, U, C, H, I, N, G(1968)$, capturas de imagem.

No caso do filme de Barlow, Hay e Robbins, o ator não mutila seus próprios olhos, mas uma pseudofiguração da mutilação, no que parece como um simulacro de um olho 
encapsulado em cena banal de homem fazendo a barba. Já no filme de Sharits, a sátira da enucleação já vem mais carregada com o desconforto presente no ambiente da contracultura, em fase do underground mais interessada na densidade do sentido da imagem do que convenções cinematográficas já estabelecidas.

Os postulados da visão, da enucleação e a figuração da automutilação estiveram também presentes em The cage (1947), dentro uma série de produções universitárias que Peterson coordenou e dirigiu na California School of Fine Arts, num projeto chamado Workshop 20. Neste filme, um pintor retira seu globo ocular na tentativa de expandir sua capacidade de visão. 0 globo ocular toma então vida própria pois, libertado do jugo opressor de seu proprietário, torna-se um flâneur pelo mundo, modificando ou fazendo evoluir sua capacidade de visão, enxergando os fenômenos de maneiras bastante inventivas: ver para frente, para trás, em slow motion e ver fora de sequências temporais diacrônicas.

Figuras 24 e 25 - Olho liberto e visões subvertidas.
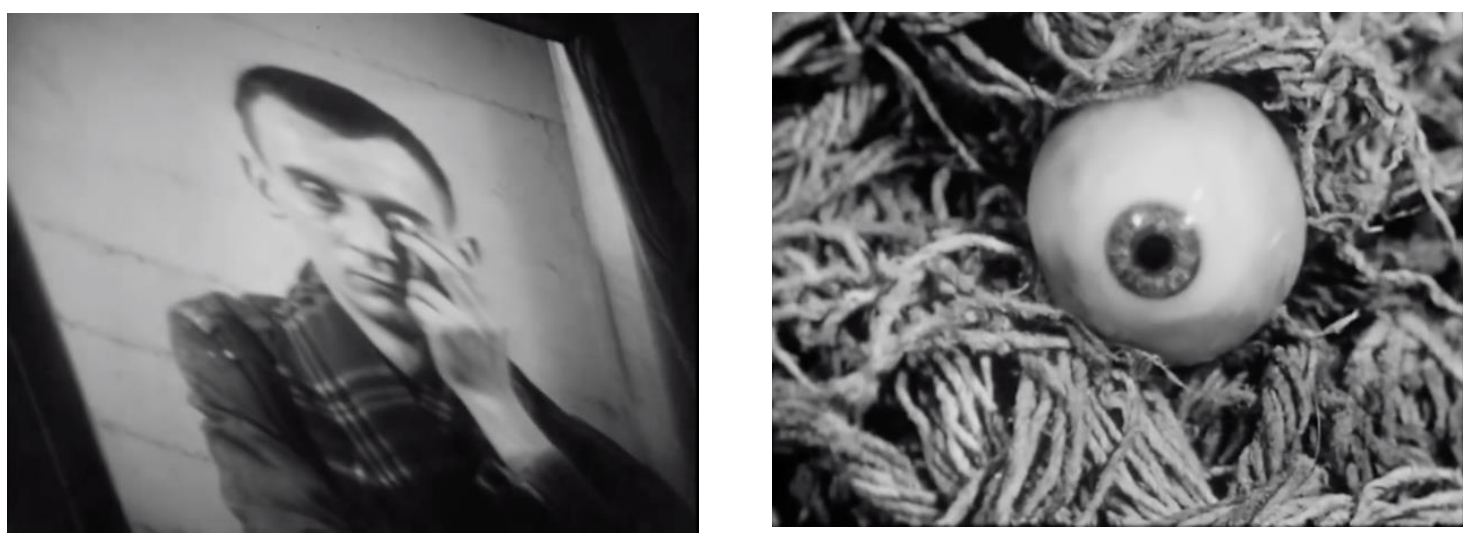

Fonte: The cage (1947), capturas de imagens.

Esse olho, mais do que a trama burlesca de The cage pode sugerir, reitera que a visão humana é portadora de um poder sobre os postulados do tempo e do espaço, estes, provenientes da cultura, são criações mentais mais do que dados "reais". Por fim, nessa proposta de uma (quase) arqueologia atoral experimental presente nesta intercambialidade figurativo explícita, chegamos, provisoriamente, a Julio Bressane que, ao lado de Jean-Luc Godard, parece ter sido um dos grandes pesquisadores da arte do ator. Isto pode ser comprovado pelo repertório profundo que Bressane apresenta dentro de sua vasta obra, retomando numa verve intersemiótica de genealogias gestuais e transformando sua obra num paideuma de referências metacinemáticas. No filme Sermões, a história de Antônio 
Vieira (1989), há uma cena de um corte do olho, retirada de um arcabouço anterior a Buñuel-Dalí, mas ainda dentro das hostes experimentais: Os nibelungos de Fritz Lang, de 1924. Bressane recria esse eco gestual em verve anárquica, mas anacronicamente saudosista acima de tudo, da cirurgia da crueldade de Buñuel-Dalí/Lang, levando suas pesquisas a recriar ou transluciferar (termo de Jairo Ferreira) a figuração da automutilação.

Figuras 26 e 27 - Bressane e seu paideuma figural: a cena do olho cortado.
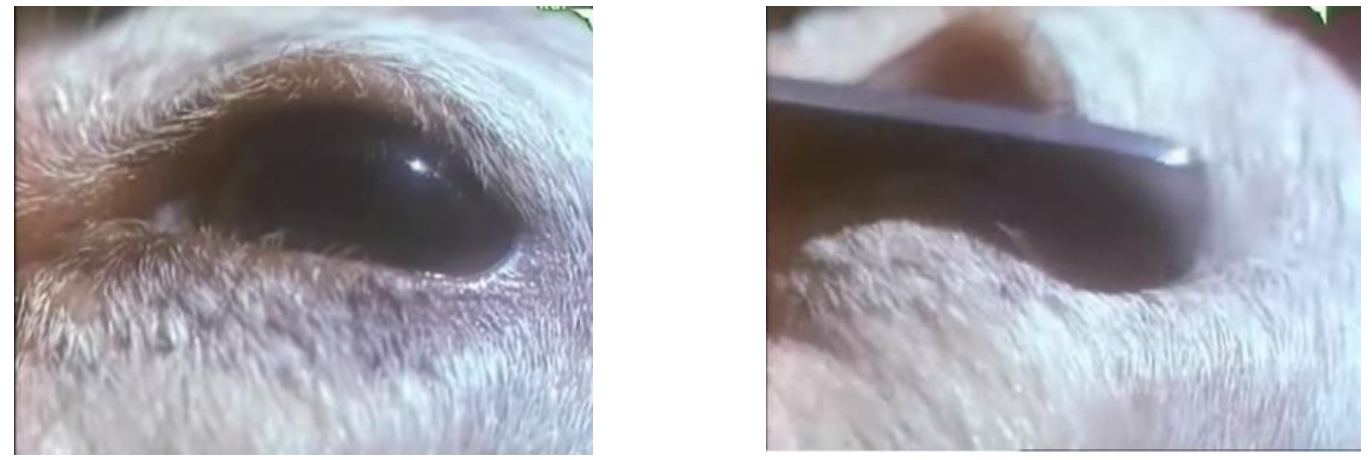

Fonte: Sermões, a história de Antônio Vieira (1989), capturas de imagens.

Bernadette Lyra (1995, p. 41) reitera o fato de que o cinema de Bressane é "puro olho, [...] [pois] existe em estado selvagem", neste ritual gestual da navalha que pode ser considerado como um resumo e retomada em tom de homenagem de toda uma linhagem de figurações presentes no cinema experimental.

Esses realizadores e atores aqui enumerados organizaram nos seus trabalhos uma verdadeira memória dos motivos visual e corporal da gestualidade da mutilação ocular, permitindo-lhes conservar e restituir plena e duradouramente este patrimônio gestual - até então simplesmente descrito, reproduzido ou apreendido pela ciência médica nas suas cirurgias oftalmológicas -, "graças ao registro do movimento ao mesmo tempo pelo intermédio de seu próprio substrato corporal e sobre o suporte material do filme" (DAMOUR, 2014, p. 23). Desta forma, ao retomarem o gesto da mutilação ocular e suas variantes, esses diretores e atores realizam quase uma antropologia do jogo do ator experimental no cinema, fieis que são à tese do olho humano como vetor transmissor de uma série de questões importantes para a fatura dos filmes de vanguarda ou experimentais: o olhar sub judice e o dispositivo exposto nas suas (in)capacidades de retratar ou registrar o "real". 


\section{Referências}

A IDADE do ouro. Direção: Luís Buñuel. Roteiro: Luís Buñuel e Salvador Dalí. 1930. (60 min.), mono, p. \& b.

ALBERA, François. L'Avant-Garde au cinéma. Paris: Armand Colin, 2005.

AMOR louco. Direção: Júlio Bressane. Roteiro: Júlio Bressane. 1971. (85 min.), mono, p. \& b.

AUMONT, Jacques. À quoi pensent les films. Paris: Séguier, 1996.

BORDWELL, D.; THOMPSON, K.; STAIGER, J. The classical Hollywood cinema. Film style \& mode of production to 1960. London: Routledge, 2005.

BRAKHAGE, Stan. Metaphors on vision. Denver: University of Colorado: Filme Culture, 1963.

BRENEZ, Nicole. L'Ange noir - Plastiques du négatif dans le cinema expérimental. In: De la figure en général e du corps en particulier - L'invention figurative au cinema. Louvain-laNeuve - Bégica: De Boeck, 1998.

COMOLLI, Jean-Louis. Ver e poder, a inocência perdida: cinema, televisão, ficção, documentário. Belo Horizonte: Editora UFMG, 2008.

DAMOUR, Christophe. La déploration, de Sarah Bernhardt à Al Pacino. Permanence et migration d'une posture codifiée (arts visuels, théâtre, cinéma). Cinémas Revue d'études cinématographiques, Montréal, v. 25, n. 1, p. 17-37, 2014.

DAMOUR, Christophe; VALMARY, Hélène; VIVIANI, Christian (dir.) Généalogies de l'acteur au cinéma. Echos, influences, migrations. Cycnos, Nice, vol. 27, n. 2, p. 9-18, 2011.

DUBOIS, Phillipe. Cinema, vídeo, Godard. São Paulo: Cosac \& Naify, 2004.

EVEN as you and I. Direção: Roger Barlow, Harry Hay e Leroy Robbins. Roteiro: não creditado. 1937. (12 min.), mono, p. \& b.

FAMÍLIA do barulho. Direção: Júlio Bressane. Roteiro: Júlio Bressane. 1970. (75 min.), mono, p. \& b.

FERREIRA, Jairo. Cinema de invenção. São Paulo: Limiar, 2000.

FUNERAL parade of roses. Direção: Toshio Matsumoto. Roteiro: Toshio Matsumoto. 1969. (105 min.), mono, p. \& b.

GODARD, Jean-Luc. Défense et illustration du découpage classique. Cahiers du Cinéma, Paris, n. 15, Tome III, p. 33-49, set. 1952.

KITTLER, Friedrich. Optical media: Berlin lectures 1999. Cambridge: Polity Press, 2010.

LYRA, Bernadette. A nave extraviada. São Paulo: Annablume: ECA-USP, 1995. 
MAUSS, Marcel. As técnicas do corpo. In: Sociologia e antropologia. São Paulo: Cosac \& Naify, 2003.

MITRY, Jean. Le cinema expérimental - histoire et perspectives. Paris: Editions Seghers, 1974.

O ENCOURAÇADO Potemkin. Direção: Serguei Eisenstein. Roteiro: Serguei Eisenstein, Nina Agadzhánova-Shutkó, Nicolai Asseiev, Sergei Tretyakov. 1925. (74 min.), mono, p. \& b.

O REI do baralho. Direção: Júlio Bressane. Roteiro: Júlio Bressane. 1974. (90 min.), mono, p. $\& b$.

REFLECTIONS on black. Direção: Stan Brakhage. Roteiro: Stan Brakhage. 1955. (12 min.), mono, p. \& b.

RENAN, Sheldon. An introduction to the American Underground film. New York: E. P. Dutton, 1967.

SERMÕES: A história de Antônio Vieira. Direção: Júlio Bressane. Roteiro: Júlio Bressane. 1989. (80 min.), dolby, color e p. \& b.

SITNEY, P. Adams. Visionary film - The American avant-garde. New York: Oxford University Press, 1980.

SITNEY, P. Adams (ed.) The avant-garde film - A reader of theory and criticism. New York: Anthology Film Archives, 1987. (Col. Anthology Film Archives \#3).

TEIXEIRA, Francisco E. 0 cineasta celerado. A arte de se ver fora de si no cinema poético de Júlio Bressane. São Paulo: Annablume, 2011.

THE CAGE. Direção: Sidney Peterson. Roteiro: não creditado. 1947. (28 min.), mono, p. \& b.

THE WAY to shadow Garden. Direção: Stan Brakhage. Roteiro: Stan Brakhage. 1955. (10 min.), mono, p. \& b.

T,O,U,C,H,I,N,G. Direção: Paul Sharits. Roteiro: não creditado. 1968. (12 min.), mono, p. \& b.

TRAITÉ de bave et d'éternité. Direção: Isidore Isou. Roteiro: não creditado. 1952. (125 min.), mono, p. \& b.

TYLER, Parker. Underground Film - a critical history. Nova York: Da Capo Press, 1995.

UM CÃO Andaluz. Direção: Luis Buñuel, Salvador Dalí. Roteiro: Luis Buñuel, Salvador Dalí. 1929. (21 min.), mono, p. \& b.

VELOSO, Geraldo. Por uma arqueologia do "outro" cinema. Estado de Minas, Belo Horizonte, 17 mai. 1983-14 jun. 1983.

VISUAL training. Direção: Frank Zwartjes. Roteiro: não creditado. 1969. (08 min.), mono, p. $\& b$. 
WEES, William C. Light Moving in Time: Studies in the Visual Aesthetics of Avant-Garde Film. Berkeley: University of California Press, 1992.

\title{
From Eisenstein to Bressane: genealogies of an experimental gesture.
}

\begin{abstract}
The art of acting occupies the center of expressive concerns that are the main pillar of researches within what is conventionally called experimental cinema. Countless filmmakers and actors used a vast palette of figurative processes to express a theme that permeates almost the entire history of experimental cinema: the act of seeing through the cinematographic device and by human vision (character / viewer). This article describes how actors and directors promoted this figurative investigation into the motif of the eye mutilation and its variables (enucleation, haemolacria, interferences and ophthalmologic surgeries) in productins outside the theoretical framework of classic cinemas.
\end{abstract}

\section{Keywords}

Actor. Cinema. Experimental. Eye mutilation.

\section{Autoria para correspondência}

Sandro de Oliveira

nagysandro1@gmail.com

\section{Como citar}

OLIVEIRA, Sandro de. De Eisenstein a Bressane. Intexto, Porto Alegre, n. 52, e-104546, jan./dez. 2021. DOI: http://dx.doi.org/10.19132/1807-8583202152.104546

Recebido em 20/06/2020

Aceito em 30/12/2020 